\title{
LXIV. Analysis of the Bohemian glass as found in the combustion tubes employed in organic analysis
}

\section{Mr. Thomas Rowney}

To cite this article: Mr. Thomas Rowney (1847) LXIV. Analysis of the Bohemian glass as found in the combustion tubes employed in organic analysis, Philosophical Magazine Series 3, 30:203, 421-424, DOI: $10.1080 / 14786444708645421$

To link to this article: http://dx.doi.org/10.1080/14786444708645421

冓 Published online: 30 Apr 2009.

Submit your article to this journal $[\pi$

Џll Article views: 2

Q View related articles $\sqsubset$ 
LXIV. Analysis of the Bohemian Glass as found in the Combustion Tubes employed in Organic Analysis. By Mr. Thomas Rowney*.

THE difficultly fusible variety of Bohemian glass has been 1 repeatedly the subject of chemical investigation. We are indebted to Berthier †, Dumas $\ddagger$, Gras $\S$, and lately Peligot ${ }^{6}$ for an analysis of this substance. The glass analysed by these chemists was of the kind usually employed in the manufacture of Bohemian goblets, an art in which Bohemia has excelled for centuries.

It appeared desirable to compare with the results of these analyses the composition of the glass which is used for the combustion of organic substances, and which likewise is chiefly manufactured in Bohemia. The properties most valued in this variety of glass are essentially different from those sought for in other kinds, and it was to be expected that this material, which has so greatly contributed to the progress of organic chemistry, and upon which the German manufacturers have of late bestowed so much attention, would also show some marked peculiarity of composition.

The following analysis was made in the laboratory of the Royal College of Chemistry. The glass was selected from the stock of the laboratory, recently imported from Germany, and which numerous trials had proved to be of first-rate quality. The tubes, though perfectly tractable in an energetic blowpipe flame, scarcely altered their form during the longest combustion in a strong charcoal fire; they never cracked during the process, even on suddenly increasing the temperature, and not uncommonly the same tube could be employed repeatedly in analysis.

A careful qualitative examination of the specimen having proved the presence of silicic acid, lime, sesquioxide of iron, alumina, oxide of manganese, magnesia, soda and potassa, the quantitative determination was proceeded with.

\section{a. Determination of Silicic Acid.}

The finely-powdered glass was ignited with carbonate of soda, treated with hydrochloric acid in excess, evaporated to dryness, once more ignited and digested with hydrochloric acid, after which all the silicic acid remained insoluble; it was collected on a filter, washed, ignited and weighed.

I. $2 \cdot 1890$ grms. of glass gave $1.5946 \mathrm{grm}$. silicic acid.

II. 2.1284 grms. of glass gave $1.5628 \mathrm{grm}$. silicic acid.

* Communicated by the Chemical Society; having been read Dec. 21, 1846.

+ Gmelin's Handbuch, vol. ii. 366 .

‡ Dumas' Traité de Chémie, vol. ii. 528. 


\section{b. Determination of Lime.}

The acid filtrate from the silicic acid was neutralized by ammonia, then slightly acidulated with acetic acid and precipitated by oxalate of ammonia, and the oxalate of lime converted into carbonate in the usual manner. lime.

I. $2 \cdot 1890$ grms. of glass gave $0.4203 \mathrm{grm}$. of carbonate of lime.

II. $2 \cdot 1284$ grms. of glass gave $0 \cdot 3843 \mathrm{grm}$. of carbonate of

\section{c. Determination of Alumina and Sesquioxide of Iron.}

To the liquid filtered from the precipitate of oxalate of lime (b.), containing a large quantity of chloride of ammonium, ammonia was added in excess, by which alumina and sesquioxide of iron were precipitated and the oxide of manganese and magnesia were retained in solution. The joint precipitate of alumina and sesquioxide of iron was collected, washed, ignited and weighed; then dissolved in hydrochloric acid and thrown down with potassa, which kept the alumina in solution. The precipitate of sesquioxide of iron (thus obtained), once more dissolved in hydrochloric acid and reprecipitated by ammonia, was now collected, ignited and weighed; the difference in the amount of the two weighings gave the amount of the alumina thus:-

$2 \cdot 1890 \mathrm{grms}$. of glass gave $0.0096 \mathrm{grm}$. of mixed oxides and $0.0029 \mathrm{grm}$. of sesquioxide of iron; the difference, 0.0067 grm., is the amount of alumina.

\section{d. Determination of Oxide of Manganese.}

This oxide was thrown down by carbonate of soda as carbonate of manganese, from the filtrate, separated from the oxide of iron and alumina (c.); the precipitate was washed, dried, ignited, and calculated as the compound oxide and sesquioxide of manganese $\left(\mathrm{Mn}_{3} \mathrm{O}_{4}\right)$.

I. $2 \cdot 1890$ grms. of glass gave $0 \cdot 0114$ grm. of the abovenamed double oxide.

II. $2 \cdot 1284$ grms. of glass gave $0.0160 \mathrm{grm}$. of the double oxide.

\section{e. Determination of the Magnesia.}

The filtrate from the carbonate of manganese $(d$.$) was pre-$ cipitated by phosphate of soda; the phosphate of magnesia and ammonia was washed, dried, ignited and weighed as pyrophosphate of magnesia.

I. $2 \cdot 1890$ grms. of glass gave $0 \cdot 0127 \mathrm{grm}$. of pyrophosphate of magnesia. 
II. $2 \cdot 1284 \mathrm{grms}$ of glass gave $0.0177 \mathrm{grm}$. of pyrophosphate of magnesia.

\section{f. Determination of the Alkalies.}

To determine the amount of the alkalies, a portion of the glass was fused with hydrate of baryta; the fused mass was digested in hydrochloric acid, evaporated to dryness and ignited, the residue again digested in hydrochloric acid, and then filtered from the insoluble silicic acid. Carbonate of ammonia was then added to the filtrate, to separate the alumina, sesquioxide of iron, baryta and lime; the solution filtered from the precipitate was evaporated to dryness and ignited, to drive off the ammoniacal salts, and the magnesia separated by means of baryta; the excess of baryta was separated by means of carbonate of ammonia, and filtered. The filtrate, evaporated to dryness and ignited, yielded the mixed chlorides of the alkaline metals; they were dissolved in water, bichloride of platinum added, and the solution evaporated to dryness on a water-bath; the residue was digested in strong alcohol, when the potassio-chloride of platinum remained undissolved; it was collected on a weighed filter, washed with alcohol, and dried in a water-bath until it ceased to lose weight. The filtrate from the potassio-chloride of platinum was evaporated to dryness, and, after the addition of some oxalic acid to the residue, ignited till it was completely decomposed; the residue was digested in water, filtered, and the filtrate evaporated to dryness in a weighed capsule; its increase in weight gave the quantity of chloride of sodium.

$1.5645 \mathrm{grm}$. of glass gave $0.9330 \mathrm{grm}$. of potassio-chloride of platinum, and $0.0905 \mathrm{grm}$. of chloride of sodium.

From the results enumerated, the calculated per-centage is as follows:-

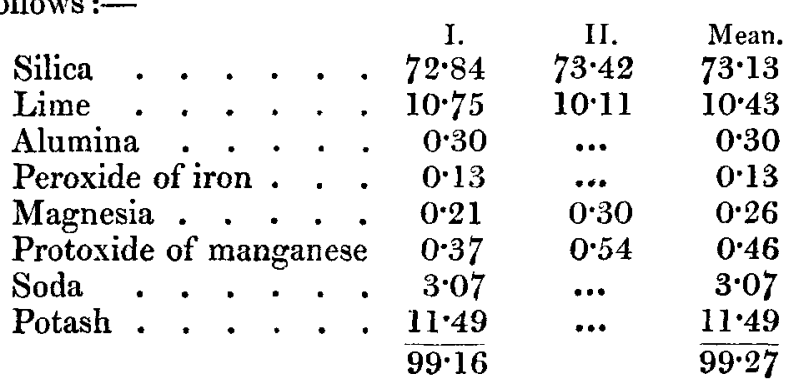

The amount of oxygen in the bases stands to the amount of oxygen in the silicic acid nearly as $1: 6$.

From the preceding analysis, it results that the composition of the glass for combustion-tubes does not differ very much 


\section{Prof. J. R. Young on a Theorem of Euler in reference}

from the material employed in goblets, as may be seen from the following comparison with the results of the chemists formerly named:-

\begin{tabular}{|c|c|c|c|c|c|}
\hline & & Berthier. & Dumas. & $\begin{array}{c}\text { Gras. } \\
71 \cdot 6\end{array}$ & $\begin{array}{l}\text { Peligot. } \\
76\end{array}$ \\
\hline $\begin{array}{l}\text { Silicic acid } \\
\text { Lime }\end{array}$ & . $\cdot$ & $\begin{array}{l}71 \cdot 7 \\
10 \cdot 3\end{array}$ & $\begin{array}{r}69 \cdot 4 \\
9 \cdot 2\end{array}$ & & $\begin{array}{r}76 \\
8\end{array}$ \\
\hline Alumina & . & . $\quad 0.4$ & $9 \cdot 6$ & $2 \cdot 2$ & 1 \\
\hline Sesquioxide & of iron & 0.3 & $\ldots$ & $3 \cdot 9$ & \\
\hline Oxide of $\mathrm{ma}$ & nganes & $0 \cdot 2$ & ... & $0 \cdot 2$ & \\
\hline Magnesia . & - & $\ldots$ & $\ldots$ & $2 \cdot 3$ & \\
\hline Soda & . & $2 \cdot 5$ & $\cdots$ & $\cdots$ & \\
\hline Potassa & . & - $12 \cdot 7$ & $11 \cdot 8$ & $11 \cdot 0$ & 15 \\
\hline & & $\overline{98 \cdot 1}$ & $100 \cdot 0$ & $101 \cdot 2$ & $\overline{100}$ \\
\hline
\end{tabular}

In one of the last numbers of Dr. Otto's German translation of Professor Graham's Elements of Chemistry, recently published, I find the analysis of a combustion-tube enumerated, performed in the laboratory of Dr. Otto, which has not yet been published in the Journals. He obtained the following results :-

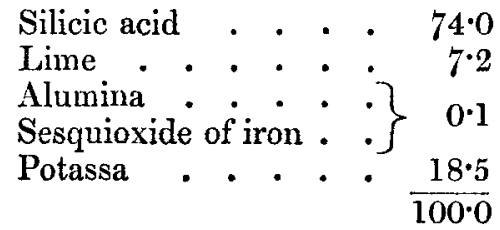

The oxygen in the bases of this glass stands to the oxygen in the silicic acid likewise as $1: 6$. Soda is entirely absent, and completely replaced by potassa. The presence however of a small amount of soda does not seem to be injurious to the glass.

LXV. On a Generalization of a Theorem of Euler in reference to the Products of the Sums of Squares. By J. R.Young, Professor of Mathematics in Belfast College*.

THE recent researches of Sir W. R. Hamilton, of Profes1 sors Graves and De Morgan, and of Messrs. J. T. Graves and Cayley, in reference to the new analytical theory of imaginary quantities, have revived attention to Euler's theorem, that the sum of four squares multiplied by the sum of four squares produces the sun of four squares; to which theorem an extension was given by Lagrange, by the introduction of coefficients into the component squares.

These recent researches bave suggested the inquiry as to

* Communicated by the Author. 